\title{
The Life Cycle of Bare Branch Families in China: A Simulation Study
}

\author{
Quanbao Jiang* \\ Zhen Guo \\ Shuzhuo Li \\ Marcus W. Feldman
}

\begin{abstract}
China is characterized by a large number of men who are unable to marry, often referred to as "bare branches." In this paper, we define the bare branch family and divide its life cycle into three stages: the unmarried co-resident with both parents, co-resident with a surviving parent, and living alone. As the childbearing age of parents increases, the age of a bare branch at the death of his parents decreases, and the duration of his living alone lengthens. An increase in the mother's childbearing age, holding that of the father constant, shortens the stage of co-residence with both parents, and lengthens the stage of living alone.
\end{abstract}

Keywords: bare branch, family life cycle, life table, simulation, surviving alone, China.

\section{Résumé}

La Chine est caractérisée par un grand nombre d'hommes qui ne peuvent pas se marier, qui sont souvent appelés « les branches nues ». Dans cet article, nous cernons la famille de branches nues et en divisons le cycle de vie en trois phases, notamment le co-résident non marié avec ses deux parents, le co-résident avec le parent survivant et enfin le célibataire vivant seul. Au fur et à mesure que l'âge de procréation des parents augmente, l'âge de la branche nue diminue au moment du décès de ses parents et la durée de sa vie vécue seul augmente. L'augmentation de l'âge de procréation de la mère, celui du père demeurant constant, raccourcit la phase de co-résidence avec les deux parents et rallonge la phase pendant laquelle la branche nue vit seule.

Mots-clés : branche nue, cycle de vie de la famille, table de vie, simulation, survivant seul, la Chine.

\section{Introduction}

In the early 1970s, China's government launched the so-called "later, longer, fewer" population policy, aimed at controlling the birth rate and population growth. In 1980, the one-child policy was proposed, and implemented with economic and financial incentives as well as coercive measures, resulting in a dramatic decline in fertility (Short et al. 2000; Nie and Wyman 2005). With stringent implementation of this policy, together with the widespread availability of ultrasound B machines,

* Quanbao Jiang, Institute for Population and Development Studies, School of Public Policy and Administration, Xi'an Jiaotong University, Xi’an, Shaanxi Province, 710049, China. Email: recluse_jqb@126.com. With Zhen Guo, School of Management, Xi'an Jiaotong University (China); Shuzhuo Li, Institute for Population and Development Studies, School of Public Policy and Administration, Xi'an Jiaotong University (China); and Marcus W. Feldman, Morrison Institute for Population and Resource Studies, Stanford University (USA). 
Jiang et al.: The life cycle of bare branch families in China-A simulation study

China's sex ratio at birth has been rising continuously. In a society with such a strong son preference and the concomitant unfavorable social status of females, when gender and number of children were in conflict, people turned to sex-selective abortion to ensure at least one son. In 2000, the sex ratio at birth in those " 1.5 children policy" areas, where a second child was permitted if the first was a girl, was 124.7, namely, 15.7 percentage points higher than that in two-children areas, where it was 109.0 — clearly indicating that sex-selective abortion was being practiced (Gu et al. 2007). A higher than normal sex ratio at birth and excess female child mortality result in a large number of missing females and an imbalance in the sex structure of the total population. For the present and in the future, there are and will be millions of young males who are unable to find brides in China (Tuljapurkar et al. 1995; Poston and Glover 2005; Attané 2006; Li et al. 2006; Jiang et al. 2007). Single males who are unable to find brides are termed bare branches (Hudson and den Boer 2004; Jiang and Li 2009).

Traditionally in China, marriage is the symbol of adulthood and signifies the start of a family, and of the subsequent parent-child relationship. Bare branches cannot establish their own family, so they lack most of the corresponding kinship-marriage ties, and have no direct descendants (Jiang and Li 2009). China is a family-centered society in which people, especially rural people, rely on family members for daily care and old age support. With the imbalance in the sex ratio, an increasing number of males will be unable to marry, and will live without the support normally provided by wives and children. Without a spouse or offspring, they maintain contact primarily with family members and relatives for emotional and functional support (Mo 2005). Compared with married men, single men in China are at a disadvantage when it comes to income, assets, and health. Even worse, those who are unable to marry will be less educated and clustered in poorer areas. All these factors increase their need for support (Ebenstein and Sharygin 2009; Das Gupta et al. 2010). Parents are the most likely people to provide support, and for the convenience of having their parents' instrumental support, bare branches arrange their lives around the health of their parents. If their parents are alive and healthy, they usually co-reside with them. Otherwise they live alone (Wei et al. 2008; Gao 2009). In this paper, a bare branch family will refer to the family of one bare branch living with his parents. In this sense, a bare branch family is quite different from traditional families, as the bare branch son lives with his parents for emotional and functional support, and possible economic support as well, and he will not establish his own family and leave his parents' family.

The impact of large numbers of bare branches on social stability has aroused wide concern (Hudson and den Boer 2004; Jiang and Li 2009), but little attention has been paid to their families, and even less is known about the length of their co-residence and how long they will live alone. As bare branches live with their parents, from whom they obtain daily care while they are alive and healthy, and live alone after their parents' death, it is important to study the life cycle of such bare branch families and estimate how long they are expected to co-reside with their parents. The division of their life cycle into stages and estimation of the lengths of these stages may not only help us understand characteristics of bare branch individuals and families, but also lay a foundation for further study of this group. In this paper, we first compare traditional nuclear families and bare branch families, and define the life cycle of bare branch families. We divide the life cycle into three stages, and then estimate the length of each stage using simulation methods. Finally, we discuss implications of these results for future policies regarding bare branches. 


\section{Life cycle stages of bare branch families}

Conventional theories concerning family life cycles focus primarily on traditional nuclear families. Demographic events in such families comprise marriage, childbearing, upbringing of children, children leaving home, and death of spouses (Glick 1977). But this model cannot be applied to unstable, incomplete, and remarriage families and is not universally applicable to Chinese families, since it does not cover stem families, which accounted for 21.37 percent of all Chinese families in 2000. It also does not include single parent families, which make up 5.52 percent of Chinese families in 2000 (Yu and Liu 2007). The correlation between family types and culture makes it difficult or even impossible to apply Western life cycle models directly to the Chinese situation. These models must be adjusted to fit the Chinese contexts.

Compared with traditional nuclear families, bare branch families are different in the following respects. First, traditional nuclear families consist of a couple and their children, whereas bare branch families comprise a bare branch and his parents. Second, the traditional family life cycle begins with the formation of a new family, then emotional separation from parents, and marriage, while the life cycle of bare branch families starts from the age at which bare branch status is defined. When the passively unmarried male exceeds the commonly recognized late marriageable age, his family (including himself and his parents) becomes a bare branch family. Third, the study objects for traditional family life cycles are demographic events such as childbearing, upbringing, and children leaving home, but bare branch families do not experience such events. The main events in bare branch families are deaths, which mark the life cycle stages in these families.

In a family-centered society like China, a marriage is never a personal matter, but a major event for the whole family (Mo 2005; Wei et al. 2008). Parents regard it as their responsibility to make marriage arrangements for their children, and if they cannot fulfill this obligation for one or more of their sons, they feel guilty on behalf of their unmarried son(s). Further, if all their sons are forced to remain single, they feel guilt not only toward these sons but also to their ancestors because they cannot carry on the family lineage (Mo 2005). In Chinese ideology, parents provide all kinds of support for their children; whether these children are adult or not, children's needs have the highest priority. Bare branches have no kinsmen by affinity and no direct offspring, so they rely heavily on their closest relatives for instrumental and emotional support. Thus, the most convenient way to receive daily care and functional support from parents is to co-reside with them (Jiang and Li 2009).

There have been some surveys of China's bare branches. Mo (2005) interviewed bare branches' family members in Jilin, Shaanxi, and Henan provinces, but these interviews focused on the behavior of the bare branches. A recent survey of 364 villages in 28 provinces in China focused on security issues (Jin et al. 2012). Another qualitative survey emphasized the negative effect of bare branches on family members in terms of family relations and psychological stress (Wei et al. 2008).

According to in-depth interviews of 22 single men aged 28 and over-carried out in 2007 by the Institute for Population and Development Studies, Xi'an Jiaotong University, in several villages in Henan province in central China - seven bare branches lived alone, nine bare branches co-resided with one parent, three bare branches lived with both parents, and three bare branches lived with other relatives. Among the seven bare branches who lived alone, four bare branches had lost both parents. Another bare branch was a bricklayer aged 55, whose mother did not live with him but with his brother because he migrated for work most of the time. Another was 46 years old, 
Jiang et al.: The life cycle of bare branch families in China-A simulation study

and his father, who was unable to work and needed instrumental support, lived with his brothers and sisters in turn. Only one bare branch had both parents alive, and they lived with his married younger brother. For the nine bare branches who co-resided with only one parent, the other parent had died. The three bare branches living with both had all their siblings married. Among the three living with other relatives, two bare branches had no surviving parent and lived with his brother's family, and another bare branch lived with both of his parents and an older brother who was also a bare branch.

In another survey on population dynamics, household livelihood, and environment change in western China, implemented by the Institute for Population and Development Studies, Xi'an Jiaotong University, in 2008 (Li and Tai 2009; Li et al. 2010a), 136 households had single sons over 26 years old, of whom 68 lived with both parents, 33 lived with one surviving parent, 18 lived alone, and 17 lived with other relatives.

Thus, most bare branches tend to live with their parents or a surviving parent, or alone. In a bare branch's family, the death of a parent is an important event that exerts a profound effect on family income, consumption, production, livelihood, social network, etc. (Wei et al. 2008; Jiang and Li 2009). When both parents are alive, they are usually not too old to work in the fields and provide daily care for their son. Moreover, these parents can obtain outside aid from their social network to help their son. The bare branch is still young, and can support himself, and even his parents, financially. At this stage, parents and bare branches suffer less pressure economically and psychologically. When one parent dies, both the surviving parent and the bare branch himself are aging, the parent can provide less daily care and works less in the fields. Also the bare branch himself will earn less. When both parents die, the bare branch has to rely on himself for daily life and is likely to suffer economic and psychological pressure (Jiang and Li 2009; Li et al. 2010b). We divide the life cycle of bare branch families into the three stages shown in Table 1, namely, co-residence with both parents, co-residence with one surviving parent, and living alone. Death is the cut-off point. When a bare branch exceeds a commonly recognized certain late marriageable age, i.e., the age at which he begins to be called a bare branch, usually 27 or 28 years old (Liu et al. 2012; Jiang and Sánchez Barricarte 213), the family is labeled as a bare branch family and enters the first stage, where the bare branch co-resides with his parents. As time goes by, one parent dies and the bare branch lives with the surviving parent; this is the second stage. Finally, the surviving parent dies and the bare branch lives alone until he himself dies and the family dissolves.

Table 1. Life cycle of bare branch families.

\begin{tabular}{|c|c|c|c|}
\hline Stages & Starting point & Ending point & Demographic events \\
\hline $\begin{array}{l}\text { Co-residence with both } \\
\text { parents }\end{array}$ & $\begin{array}{l}x \text { years of age of the } \\
\text { bare branch }\end{array}$ & Death of one parent & $\begin{array}{l}\text { Bare branch co-resides } \\
\text { with both parents, until } \\
\text { one parent dies; a family } \\
\text { of three persons }\end{array}$ \\
\hline $\begin{array}{l}\text { Co-residence with the } \\
\text { surviving parent }\end{array}$ & Death of one parent & $\begin{array}{l}\text { Death of the other } \\
\text { parent }\end{array}$ & $\begin{array}{l}\text { Bare branch lives with } \\
\text { surviving parent; a family } \\
\text { of two persons }\end{array}$ \\
\hline Living alone & $\begin{array}{l}\text { Death of the other } \\
\text { parent }\end{array}$ & $\begin{array}{l}\text { Death of the bare } \\
\text { branch }\end{array}$ & $\begin{array}{l}\text { Bare branch lives alone } \\
\text { until death; a family of } \\
\text { one person }\end{array}$ \\
\hline
\end{tabular}




\section{Method and data}

Ideally we would like to analyze the life cycle stages of bare branches empirically, with survey data on life histories or event histories. Since such data are not available, instead we use a mathematical model and simulate the length of each life cycle stage, based on available Chinese life tables.

\section{Method}

Myers (1959) used the life table in obtaining the basic formula for calculating the probability of a male losing his spouse, using a discrete age variable. Goldman and Lord (1983) made some improvements on Myers' method, designing functions for measuring widowhood and related indicators with a continuous age variable. Keyfitz and Caswell (2005) introduced life table methods for analyzing not only widowhood and related indicators, but also kinship relationships. In this paper, drawing on the methods of Goldman and Lord (1983) and Keyfitz and Caswell (2005), we design formulas to measure the length of each stage of bare branch families.

Let $l^{m}(t)$ and $l^{f}(t)$ represent the life table probabilities of surviving from birth to exact age $t$, where superscripts $m$ and $f$ denote male and female, respectively. The corresponding risk of dying at age $t$ is denoted by $\mu^{m}(t)$ and $\mu^{f}(t)$, where $\mu(t)=-l^{\prime}(t) / l(t)$. A man becomes a bare branch at age $x$, and if the age gap between the father and the bare branch is $k_{1}$, then when the son becomes a bare branch, the father is $x+k_{1}$ years old. Similarly, if the age difference between the mother and the bare branch is $k_{2}$, the mother is $x+k_{2}$ years old when the son becomes a bare branch. If the death of a relative affects one's psychological and physical health, it may affect survivorship. But such an effect is very difficult to measure, and, as a result, many studies assume that survivorship is independent of marital status and of losing a relative (Goldman and Lord 1983; Keyfitz and Caswell 2005). In what follows, we also assume that survivorship is independent of marital status and of losing a relative. The probability $P^{m}$ that a bare branch outlives his father is simply the probability that he survives $t$ years from the age at which he became a bare branch, and that his father dies at exactly $t$ years, summed over all values of $t$, which can be written as

$$
\begin{aligned}
P^{m} & =\int_{0}^{w_{1}} \frac{l^{m}(x+t)}{l^{m}(x)} \frac{l^{m}\left(x+k_{1}+t\right)}{l^{m}\left(x+k_{1}\right)} \mu^{m}\left(x+k_{1}+t\right) d t \\
& =\int_{0}^{w_{1}} f\left(x, k_{1}, t\right) d t .
\end{aligned}
$$

If the highest age in a given life table is $a$, then in (1) and (2) $w_{1}=a-\left(x+k_{1}\right)$. In our calculation, we take the highest age to be 90 , so $w_{1}=90-\left(x+k_{1}\right)$. In the same way, the probability that a bare branch eventually outlives his mother is

$$
\begin{aligned}
P^{f} & =\int_{0}^{w_{2}} \frac{l^{m}(x+t)}{l^{m}(x)} \frac{l^{f}\left(x+k_{2}+t\right)}{l^{f}\left(x+k_{2}\right)} \mu^{f}\left(x+k_{2}+t\right) d t \\
& =\int_{0}^{w_{2}} f\left(x, k_{2}, t\right) d t
\end{aligned}
$$

where $w_{2}=90-\left(x+k_{2}\right)$.

We can obtain the cumulative probability distribution function of a bare branch outliving his father in year $t$ since the age at which he became a bare branch: 


$$
F_{t}^{m}=\frac{1}{P^{m}} \int_{0}^{t} f\left(x, k_{1}, t\right) d t,
$$

while the cumulative probability distribution function of a bare branch outliving his mother can be written as

$$
F_{t}^{f}=\frac{1}{P^{f}} \int_{0}^{t} f\left(x, k_{2}, t\right) d t .
$$

Let $X_{t}$ and $Y_{t}$ denote the length of time that a bare branch co-resides with his father and his mother, respectively. Then the time a bare branch co-resides with both parents until one dies is $Z_{1, t}=\operatorname{Min}\left(X_{t}, Y_{t}\right)$, whose cumulative probability distribution function can be written as

$$
F_{\min }\left(z_{1, t}\right)=1-\left(1-F_{t}^{m}\right)\left(1-F_{t}^{f}\right) .
$$

The expected value of the time that a bare branch co-resides with both parents can be expressed as

$$
E_{1}=\int_{0}^{w} t f_{\min }(t) d t
$$

where $w=\min \left(w_{1}, w_{2}\right)$ and

$$
f_{\min }(t)=\frac{d F_{\min }\left(z_{1, t}\right)}{d t}=\frac{f\left(x, k_{1}, t\right)}{P^{m}}\left(1-F_{t}^{f}\right)+\frac{f\left(x, k_{2}, t\right)}{P^{f}}\left(1-F_{t}^{m}\right) .
$$

The time that a bare branch co-resides with at least one parent is denoted by $Z_{2, t}$, with $Z_{2, t}=\operatorname{Max}\left(X_{t}, Y_{t}\right)$, whose cumulative probability distribution function can be written as

$$
F_{\max }\left(z_{2, t}\right)=F_{t}^{m} F_{t}^{f} \text {. }
$$

Then the expected length of time a bare branch co-resides with at least one parent is $E_{2}$, with

$$
E_{2}=\int_{0}^{w} t f_{\max }(t) d t
$$

where

$$
f_{\max }(t)=\frac{d F_{\max }\left(z_{2, t}\right)}{d t}=\frac{f\left(x, k_{1}, t\right)}{P^{m}} F_{t}^{f}+\frac{f\left(x, k_{2}, t\right)}{P^{f}} F_{t}^{m} .
$$

The expected length of time a bare branch lives with only one parent is $E_{3}=E_{2}-E_{1}$. The expected time a bare branch lives alone is denoted by $E_{4}$, which can be written as $E_{4}=e_{x}^{s},(15)$ where $e_{x}^{s}$ is the expectation of life for males aged $x$, where $x$ is the age at which both parents have died, and is the age at which the third stage begins. There is quite a variety of software which can be applied for the calculation, such as Matlab, Stata, and Excel. In this paper, we used Excel to calculate the data.

\section{Data}

Data employed here include life tables and age parameters, such as the starting age of a bare branch $x$, the corresponding father's age $x+k_{1}$, and mother's age $x+k_{2}$. For life table information, the 2010 census provides the latest data, but up to now only total population size has been released and it will take quite a long time to obtain life tables for 2010 data, so we employ the 2000 census of China. The 
2000 census, although generally regarded as successful, still produced unprecedented challenges due to China's rapid socioeconomic transition; the underreporting rate is officially estimated at 1.81 percent (Census Office 2002). By international standards, this rate is acceptable, but is much higher than the 0.06 percent estimated for the 1990 census (Lavely 2001; Walfish 2001). What complicated the situation was not only underreporting but also overcounting in some age groups. The deaths enumerated in the 2000 census refer to those taking place between November 1, 1999, and October 31, 2000. The data are problematic because of the underreporting of deaths in a retrospective census. Since marital status exerts a profound influence on life expectancy and mortality patterns, we should use life tables for bare branches in the aforementioned formulas. But since life tables for bare branches and bare branch families are not available, we adopt the sex-specific life tables for the rural population developed in Li et al. (2005).

As can be seen above, ages $x, x+k_{1}$ and $x+k_{2}$ will affect the expected lengths of the three life cycle stages. In China, the legal age for marriage is 22 for males and 20 for females. The mean age at first marriage from the 2000 census is about 25 for males and 23 for females (Guo 2004; Jiang et al. 2007). No agreement has been reached on the starting age of a bare branch, some studies define 28 or older as the starting age (Jin et al. 2012; Liu et al. 2012). However, for rural males and females, even though they postpone their marriage, they also tend to become engaged at a very young age (at around 20 years old) - especially in recent years as bride price and marriage expenses have increased dramatically (Yan 2005; Zhang 2006). In most rural areas, especially in remote underdeveloped areas, people tend to marry early; most married males are married before 26, and the possibility of getting married after 26 is quite low (Wei and Zhang 2011). If a young male remains single after 25 or 26 years old, his marriage status will be regarded as a very urgent concern for his family (Wei et al. 2008). Of course, some rural males marry late voluntarily, but they account for a very small fraction of all marriages (Luo 2008). Here, we define the starting age of a bare branch as 26 years. Since other studies used different definitions, we explore the effect on the three stages of changing this age, say, to 28 and 30.

Gradually China's age at first marriage and childbearing has increased. In 1990 the age at first marriage was 23.83 years for males and 22.04 for females (Guo 2004). So for bare branches' parents (who married and gave birth before 1990), they should be married and bear at younger ages. We assume that the childbearing age is 24 for the father and 22 for the mother (a spousal age difference of 2 years consistent with most years, see Guo 2004) and investigate the effect of changing this assumption on the life cycle of bare branch families.

\section{Results}

\section{Mortality and life cycles}

We first investigate the probability that a bare branch loses his father and mother. The starting age of a bare branch is 26 years old, at which time the father is 50 years old (aged 24 at the time of birth of the bare branch) and the mother is 48 years old (aged 22 at childbearing).

\section{Age pattern of losing father and mother}

Figure 1 presents age-specific probabilities that a bare branch loses his father and mother. From age 26 to age 57, the age-specific probability of losing his father is higher than that of losing his mother. This age-specific probability remains under 0.01 from age 26 to 31, and under 0.02 from 32 to 39 , and then increases, reaching a peak at age 54 , after which the probability of losing his father de- 
clines. The age-specific probability of losing his mother remains under 0.01 from 26 to 37, increases until a peak at the age of 58 , and declines thereafter. Worth mentioning is that at the right-hand end of both curves (i.e., when the parents are 90 years old), the data show a rebound because of using the age limit of 90 years in the life table. If the life tables were extended to 105 years, neither curve would rebound (see also Goldman and Lord 1983).

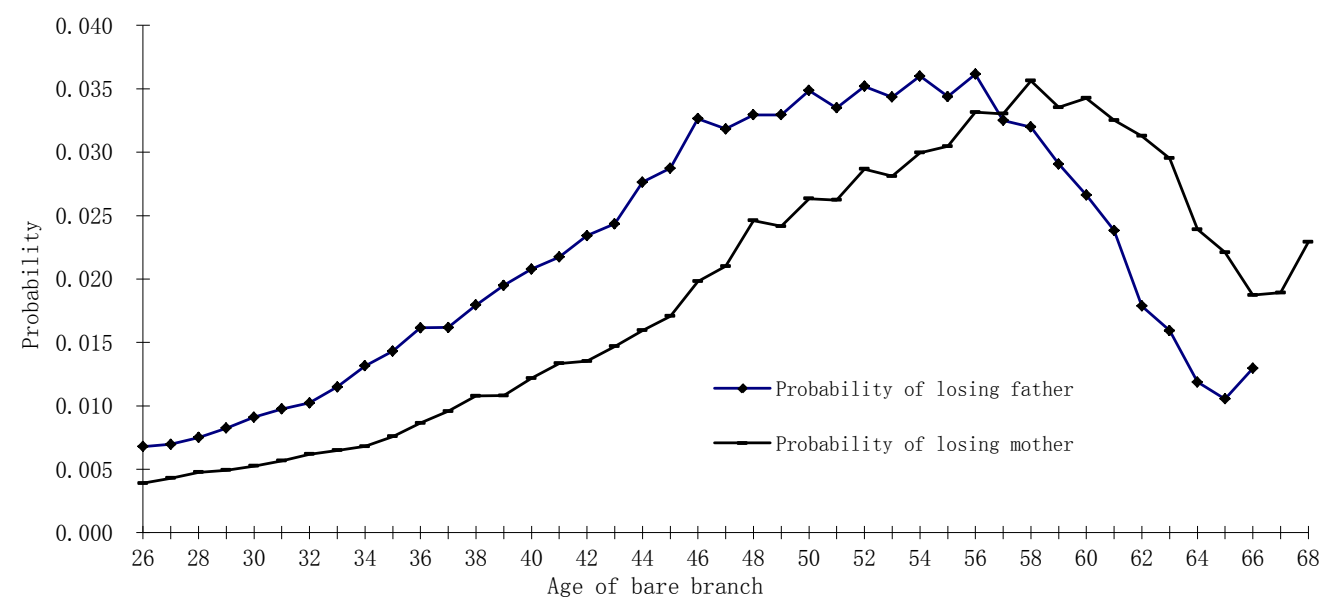

Figure 1. Age-specific probability of losing a father or a mother.

\section{Cumulative probabilities of losing father and mother}

As shown in Figure 2, at the bare branch's age of 50, the cumulative probability of losing his father is less than 0.5 , while that of losing his mother is less than 0.3. As the bare branch's age increases to 60 , the cumulative probability of losing his father reaches 0.80 , and that of losing his mother exceeds 0.60. The eventual cumulative probability of losing the father is 0.9 (when the bare branch is 66 years old), and that of losing the mother is 0.81 (when the bare branch is 68 years old). Biologically, females have a survival advantage over males, which we see in Figure 2, where the cumulative probabilities of a father's death are always higher than those of a mother's.

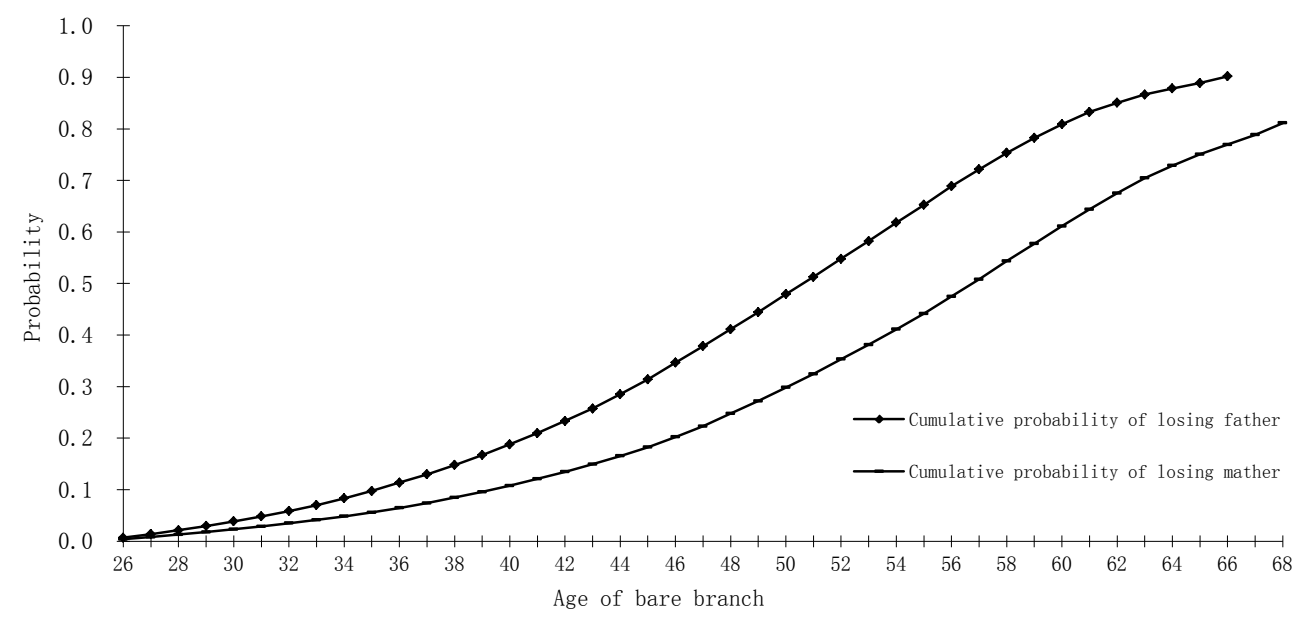

Figure 2. Cumulative probability of losing the father and mother. 


\section{Life cycle characteristics of bare branch families}

With the age at childbearing for fathers taken as 24 years, and 22 for mothers, and the starting age of a bare branch taken as 26 years old, the stage of co-residence with both parents for bare branch families lasts about 19 years, as shown in Table 2. During this stage, the father's age changes from 50 to 69 years, and the mother's from 48 to 67. In this period, the support they provide for their bare branch son can be instrumental (such as cooking, washing clothes, and cleaning), emotional, and even financial. When the bare branch is about 45 years old, one parent dies, and the family enters the second stage, namely co-residence with one surviving parent, which lasts about 11 years. At the bare branch's age of 45, his surviving parent is nearly 70 years old, and can offer him only limited instrumental, emotional, and financial support. At about 56, both parents have died and the bare branch lives alone. This final stage lasts about 16 years. During this stage, the bare branch has lost, partly or fully, his working ability either as a migrant worker or on the farm, and receives insufficient income to support himself. He will likely fall into extreme poverty because reliable social security systems do not exist in rural China.

\section{Effect of changes in parameters on the life cycle}

\section{Effect of starting age on the three stages}

Different assumptions on bare branches' starting age will result in differences in the three stages. Table 2 demonstrates the effect on the family life cycle of changing the starting age from 24 to 36 years.

Table 2. Influence of bare branch starting ages on life cycle.

\begin{tabular}{cccccc}
\hline $\begin{array}{c}\text { Starting } \\
\text { age }\end{array}$ & $\begin{array}{c}\text { Co-residence with } \\
\text { both parents (yrs) }\end{array}$ & $\begin{array}{c}\text { Bare branch's age } \\
\text { when losing one } \\
\text { parent }\end{array}$ & $\begin{array}{c}\text { Co-residence with } \\
\text { one parent (yrs) }\end{array}$ & $\begin{array}{c}\text { Bare branch's age } \\
\text { when losing the } \\
\text { other parent }\end{array}$ & $\begin{array}{c}\text { Living } \\
\text { alone }\end{array}$ \\
\hline 24 & 20.84 & 44.84 & 11.36 & 56.20 & 15.93 \\
26 & 19.26 & 45.26 & 11.05 & 56.31 & 15.98 \\
28 & 17.75 & 45.75 & 10.69 & 56.44 & 16.00 \\
30 & 16.27 & 46.27 & 10.32 & 56.59 & 16.00 \\
32 & 14.84 & 46.84 & 9.92 & 56.76 & 15.99 \\
34 & 13.45 & 47.45 & 9.50 & 56.95 & 15.96 \\
36 & 12.14 & 48.14 & 9.04 & 57.18 & 15.91 \\
\hline
\end{tabular}

Note: Father is 24 and mother is 22 at the bare branch's birth.

Table 2 shows that if the starting age of a bare branch is 24 years, then the length of the coresidence with both parents lasts about 21 years, but it declines to about 12 years if the starting age is raised to 36 years. Over the same range of starting ages, the bare branch's age at the end of the first stage and beginning the second stage increases from 44.84 to 48.14 years; this is the bare branch's age when one of his parents dies. The length of co-residence with the one surviving parent then decreases from about 11 to about 9 years. However, change in starting age has little effect on the bare branch's age at entering the third stage. After both parents die, the bare branch is expected to live alone for 16 years.

Therefore, the starting age does not have much effect on the lengths of the life cycle stages. Even if we define the starting age as 36 or older, the first stage decreases by 8.6 years. As the starting age 
Jiang et al.: The life cycle of bare branch families in China-A simulation study

varies from 24 to 36 years, the age at which the second stage is entered increases by around three years and the second stage shortens by two years, while the last stage remains at about 16 years.

\section{Effect of childbearing age on life cycle}

The intergenerational age gap has important effects on the probabilities that the spouse or offspring die (Goldman and Lord 1983; Jiang 2006). The parents' age at the bare branch's birth will also influence the probabilities of the parents' deaths and, hence, the length of the stages of the bare branch family life cycle. Table 3 shows the effect on the bare branch family life cycle of fathers' childbearing age as it ranges from 20 to 34 years.

Table 3. Influence of father's age at birth of bare branch on family life cycle.

\begin{tabular}{cccccc}
\hline $\begin{array}{c}\text { Father's } \\
\text { childbearing } \\
\text { age }\end{array}$ & $\begin{array}{c}\text { Co-residence with } \\
\text { both parents (yrs) }\end{array}$ & $\begin{array}{c}\text { Bare branches' } \\
\text { age when losing } \\
\text { one parent }\end{array}$ & $\begin{array}{c}\text { Co-residence with } \\
\text { one parent (yrs) }\end{array}$ & $\begin{array}{c}\text { Bare branches'age } \\
\text { when losing the } \\
\text { other parent }\end{array}$ & $\begin{array}{c}\text { Living } \\
\text { alone }\end{array}$ \\
\hline 20 & 22.12 & 48.12 & 11.68 & 59.80 & 12.49 \\
22 & 20.70 & 46.70 & 11.36 & 58.06 & 14.23 \\
24 & 19.26 & 45.26 & 11.05 & 56.31 & 15.98 \\
26 & 17.86 & 43.86 & 10.68 & 54.54 & 17.75 \\
28 & 16.46 & 42.46 & 10.32 & 52.78 & 19.51 \\
30 & 15.08 & 41.08 & 9.93 & 51.01 & 21.28 \\
32 & 13.73 & 39.73 & 9.51 & 49.24 & 23.05 \\
34 & 12.44 & 38.44 & 9.06 & 47.50 & 24.79 \\
\hline
\end{tabular}

Note: Mother is 2 years younger than father at the bare branch's birth.

Obviously the father-son age gap has a strong influence on each stage of the bare branch family life cycle. If a bare branch was born to a 20 -year-old father and 18 -year-old mother, his co-residence with both parents lasts about 22 years, due to the small age gap between the two generations. One of the parents dies when the bare branch is about 48 years old, and the other dies when he is almost 60, after 11 years of co-residence with one parent; hence the third stage, living alone, lasts about 12 years.

As the age at childbearing increases, the length of the first stage decreases, and so does the age of the bare branch at the death of one of his parents and the length of the second stage, while the third stage is extended. If the bare branch is born to a 34-year-old father and a 32-year-old mother, his co-residence with both parents will last only about 12 years, about ten years less than if he had been born when his father was 20 years old and his mother 18 . Then his co-residence with one parent will last nine years, over three years less, while he will live alone for 12 years longer.

\section{Effect of age gap between couples on family life cycle}

Husbands are usually older than their wives, which some claim to have a biological explanation (Davis 1998). A study of 29 developing countries confirms this typical marriage pattern (Casterline et al. 1986), and in China there is often a two to three years age gap between couples (Das Gupta and Li 1999). This age gap between couples will influence their childbearing age gap and the stages of the family cycle.

In Table 4, the father's age at which the bare branch is born is held constant at 24, and the family life cycle changes with the childbearing age of the mother. As the mother's childbearing age increases, the first and second stages will be shorter and the third stage longer, but not to a larger extent. 
Table 4. Influence of age gap between couples on family life cycle (Father 24 years).

\begin{tabular}{cccccc}
\hline $\begin{array}{c}\text { Mother's age at } \\
\text { childbearing }\end{array}$ & $\begin{array}{c}\text { Co-residence } \\
\text { with both parents } \\
\text { (yrs) }\end{array}$ & $\begin{array}{c}\text { Bare branch's } \\
\text { ages when } \\
\text { losing one } \\
\text { parent }\end{array}$ & $\begin{array}{c}\text { Co-residence } \\
\text { with one parent } \\
\text { (yrs) }\end{array}$ & $\begin{array}{c}\text { Bare branch's } \\
\text { ages when losing } \\
\text { the other parent }\end{array}$ & Living alone \\
\hline 20 & 19.76 & 45.76 & 11.11 & 56.87 & 15.42 \\
21 & 19.52 & 45.52 & 11.07 & 56.59 & 15.70 \\
22 & 19.26 & 45.26 & 11.04 & 56.30 & 15.99 \\
23 & 18.98 & 44.98 & 11.07 & 56.05 & 16.24 \\
24 & 18.70 & 44.70 & 11.16 & 55.86 & 16.43 \\
25 & 18.39 & 44.39 & 10.82 & 55.21 & 17.08 \\
\hline
\end{tabular}

\section{Conclusions}

Females are generally able to marry men of higher socioeconomic status than their own, and men who cannot find a wife tend to be from the lowest socioeconomic strata (Hesketh and Zhu 2006). With women choosing to migrate in order to make a better marriage, bare branches have become concentrated in poor areas, where they form a bare branch class, which has been reported as "bare branch villages" in the media. As the number of bare branches increases, the issue of bare branch families deserves more attention. In this paper, we define the bare branch family and its three stages. Using the 2000 census life tables, we obtained the following findings.

First, the age-specific probabilities of losing the father and mother vary as the bare branch's age changes. At 60 , the cumulative probability of losing his father reaches 0.8 , and that of losing his mother exceeds 0.6. The cumulative probability of losing father is always higher than that of losing mother.

Second, keeping the father's and mother's ages at childbearing constant, when the starting age of a bare branch increases, co-residence time with both parents shortens, as does the co-residence time with one parent. But the living alone stage changes little and remains about 16 years.

Third, variation in the parents' ages when the bare branch was born significantly affects the lengths of the three stages of the family life cycle. As these ages increase, the co-residence times with both parents and with one parent become shorter, and the living alone stage is extended. But the effect is much larger on the co-residence time with both parents and the living alone stage than on co-residence with one parent. If the age at childbearing for the father is over 30, the bare branch faces more than 20 years of living alone.

Finally, holding the father's age at birth of the bare branch constant, increasing the mother's age at childbearing shortens the co-residence time with both parents and extends the time of living alone.

Marriage is thought to improve men's health by reducing risky behavior, and because of economies of scale in nutrition and caretaking (Lillard and Panis 1996). China's Census and the China Household Income Survey (CHIS) indicate that men who fail to marry make less income, have less financial wealth, and have poorer health (Ebenstein and Sharygin 2009). As long as the bare branch's parents are alive, he can receive daily care from them. However, when one parent dies, and the bare branch himself is in his late 40s, the surviving parent is already in the 70s and obviously needs support from the bare branch while attempting to provide support for the bare branch.

As the marriage squeeze intensifies, an increasing share of males will face enforced bachelorhood and vulnerable old age. The large number of old unmarried males will bring about a crisis in old age support. They will rely heavily on publicly run facilities due to lack of support from children, and will depend more on social services than the married elderly (Wu and Pollard 1998). This will place a 
Jiang et al.: The life cycle of bare branch families in China-A simulation study

heavy financial burden on government at all levels, and will increase the potential for disaffection and social unrest (Das Gupta et al. 2010). With socioeconomic development, it is expected that the Chinese government will gradually be able to afford the support for the elderly that is now mainly given by families (Burgess 2002). Now China's social protection programs are growing quite quickly. In 2009 September, The State Council issued Instructions on Experimental Zones of New Types of Rural Social Old Age Support. This document will accelerate the building of social security systems in rural areas, and should benefit bare branches. Even today, old bare branches are regarded as 'Five Guaranteed' people and receive both material and financial support from local governments in some rural areas (Jiang and Li 2009). But social security systems will not be extended to all rural areas in the foreseeable future, and the family will be expected to provide the necessary support for quite a long time. With no support from a spouse or children, and no emotional communication with family members, old bare branches will be trapped in both material and psychological poverty (Zhu 2008).

In China, the family household is at the center of economic organization and livelihoods. The household economic fortune depends heavily on who resides within it, namely its size and structure. Life course transition and household economy have a strong relationship (Chen and Korinek 2010). Besides the emotional and functional support for the bare branches, bare branch families may still benefit economically from such co-residence from the perspective of an adaptive family strategy. As empirical studies are few for the moment, it is worthwhile to focus on this aspect in future research.

Since life table data are unavailable for bare branches, we used the life tables for the rural population instead. Since marital status affects health status and life expectation, use of the life table for the rural population rather than specifically for bare branches will affect the accuracy of our estimates. Further, the age limit in the life tables we used is 90 which affects some of our analysis, and in particular distorts the age-specific probabilities of losing the father and mother at extreme old ages. Detailed demographic study of bare branch families is needed to test whether the predictions made here fit those derived from bare branches themselves.

\section{Acknowledgment}

This work is jointly supported by National Social Science Foundation of China (08\&ZD048), the Fundamental Research Funds for the Central Universities, and 985-3 Project of Xi'an Jiaotong University.

\section{References}

Attané, I. 2006. The demographic impact of a female deficit in China, 2000-2050. Population and Development Review 32(4):755-770.

Burgess, R. 2002. Modernization and Son Preference in People's Republic of China. Manila: ADB.

Casterline, J.B., L. Williams, and P. McDonald. 1986. The age difference between spouses: Variations among developing countries. Population Studies 40(3):353-374.

Chen, F., and K. Korinek. 2010. Family life course transition and rural household economy during China's market reform. Demography 47(4):963-987.

Census Office (Census Office of the State Council). 2002. Data of the Census in 2000. Beijing: China Statistics Press. 
Das Gupta, M., and S. Li. 1999. Gender bias in China, South Korea and India 1920-1990: The effects of war, famine, and fertility decline. Development and Change 30(3):619-652.

Das Gupta, M., A. Ebenstein, and E.J. Sharygin. 2010. China's marriage market and upcoming challenges for elderly men. World Bank Policy Research Working Paper 5351. http://www-wds. worldbank.org/servlet/WDSContentServer/WDSP/IB/2010/06/29/000158349_2010062908552 0/Rendered/PDF/WPS5351.pdf

Davis, A. 1998. Age differences in dating and marriage: Reproductive strategies or social preferences? Current Anthropology 39(3):374-380.

Ebenstein, A., and E.J. Sharygin. 2009. The consequences of the 'missing girls' of China. The World Bank Economic Review 23(3):399-425.

Gao, C. 2009. The empirical study on supports of bare branch sons to their parents. MA Thesis, Xi'an Jiaotong University. (In Chinese)

Glick, P.C. 1977. Updating the life cycle of the family. Journal of Marriage and the Family 39(1):5-13.

Goldman, N., and G. Lord. 1983. Sex differences in life cycle measures of widowhood. Demography 20(2):177-195.

Gu, B., F. Wang, Z. Guo, and E. Zhang. 2007. China's local and national fertility policies at the end of the twentieth century. Population and Development Review 33(1):129-147.

Guo, Z. 2004. Reexamining China's low fertility in the 1990s. Population Research 28(4):16-24. (In Chinese)

Hesketh, T., and W. Zhu. 2006. Abnormal sex ratios in human populations: Causes and consequences. Proceedings of the National Academy of Sciences of the United States of America 103(36):13271-5.

Hudson, V., and A.M. den Boer. 2004. Bare Branches: The Security Implications of Asia's Surplus Male Population. Cambridge, MA: The MIT Press.

Jiang, Q. 2006. Measures of widowerhood and child losing in contemporary China. Paper presented at the IUSSP Seminar: Ecology of the Male Life Course. Marburg, Germany, October 10-12.

Jiang, Q., and S. Li. 2009. Female Deficit and Public Safety. Beijing: Social Sciences Academic Press. (In Chinese)

Jiang, Q., and J.J. Sánchez Barricarte. 2013. Socio-demographic risks and challenges of bare branch villages in China. Asian Social Work and Policy Review 7(2):99-116.

Jiang, Q., I. Attané, S. Li, and M.W. Feldman. 2007. Son preference and the marriage squeeze: An integrated analysis of the first marriage and the remarriage market, in Watering the Neighbor's Garden: The Growing Demographic Female Deficit in Asia, edited by I. Attané and C.Z. Guilmoto. Paris: CICRED.

Jin, X., L. Liu, Y. Li, M.W. Feldman, and S. Li. 2012. Gender imbalance, involuntary bachelors and community security: Evidence from a survey of hundreds of villages in rural China. Paper prepared for the PAA 2012 annual meeting. http://paa2012.princeton.edu/sessionViewer. aspx?SessionId $=210$.

Keyfitz, N., and H. Caswell. 2005. Applied Mathematical Demography. Springer Science + Business Media, Inc. 
Jiang et al.: The life cycle of bare branch families in China-A simulation study

Lavely, W. 2001. First impressions from the 2000 census of China. Population and Development Review 27(4):755-769.

Li, J., and X. Tai. 2009. An empirical research on the rural households vulnerability to poverty in West China based on hierarchal linear model. Modern Economic Science 31(5):110-128.

Li, S., F. Sun, Q. Jiang, X. Zou, R. Guan, and P. Hu. 2005. Mortality research on China's fifth census data. In China's Transitional Population: Collection of Monograph on 2000 Census. Beijing: China Statistics Press, pp. 94-155. (In Chinese)

Li, S., Q. Jiang and M.W. Feldman. 2006. Gender Discrimination and Population Development. Beijing: Social Sciences Academic Press. (In Chinese)

Li, C., S. Li, M.W. Feldman, and X. Tai. 2010a. The influence of labor out-migration on rural household's livelihood capital in rural mountain area of western China. Population and Economics 31(6):20-26.

Li, Y., S. Li, Y. Wei, and D. Jiang. 2010b. Marital status and social support network of rural males. Journal of Xi'an Jiaotong University(Social Sciences) 30(3):54-62. (In Chinese)

Lillard, L.A., and W.A. Panis. 1996. Marital status and mortality: The role of health. Demography 33(3):313-327.

Liu, L., X. Jin, M. Brown, and M.W. Feldman. 2012. Marriage squeeze and inter-provincial marriage in central China: Evidence from X County. Paper prepared for the PAA 2012 annual meeting. http:// paa2012.princeton.edu/sessionViewer.aspx?SessionId $=210$.

Luo, Z. 2008. Why Some Rural Males Can Not Get Married: An Exploratory Study in Central Henan Province. MA Thesis, Xi'an Jiaotong University.

Mo, L. 2005. Implications of the High Sex Ratio at Birth. Beijing: China Population Press. (In Chinese)

Myers, R.J. 1959. Statistical measures in the marital life cycles of men and women, in International Population Conference. Vienna: Christopher Reisser's Sons, pp. 229-233.

Nie, Y., and R.J. Wyman. 2005. The one-child policy in Shanghai: Acceptance and internalization. Population and Development Review 31(3):313-336.

Poston, D.L., and K.S. Glover. 2005. Too many males: Marriage market implications of gender imbalances in China. Genus LXI(2):119-140.

Short, S.E., L. Ma, and W. Yu. 2000. Birth planning and sterilization in China. Population Studies 54(3):279-291.

Tuljapurkar, S., N. Li, and M.W. Feldman. 1995. High sex ratios in China's future. Science 267:874-876.

Walfish, D. 2001. China's census: National count reveals major societal changes. Science 292 (5523):1823.

Wei, Y., and L. Zhang. 2011. The marriage dilemma of involuntary bachelors in rural China: From the perspective of gender inequality. Population Research 35(5):58-70. (In Chinese)

Wei, Y., X. Jin, and S. Li. 2008. Stress and coping in families with old unmarried male: Evidence from YC County in rural Henan China. Population and Development 14(5):2-11. (In Chinese)

Wu, Z., and M. Pollard. 1998. Social support among unmarried childless elderly persons. Journal of Gerontology: Series B: Psychological Sciences and Social Sciences 53B:324-335. 
Yan, Y. 2005. The individual and transformation of bride wealth in rural north China. Journal of Royal Anthological Institute 11:637-658.

Yu, H., and Y. Liu. 2007. Construction and empirical study of models of Chinese family life cycle. Management Study 6:45-53. (In Chinese)

Zhang, W. 2006. Who adopts girls and why? Domestic adoption of female children in contemporary rural China. The China Journal 56:63-82.

Zhu, T. 2008. The impact of imbalanced sex structure on rural future elderly support. Northwestern Population 3:121-124. (In Chinese) 